\title{
Lenguaje, ciencia y metaforización de la realidad: aproximaciones a la estética del lenguaje científico en Nietzsche
}

\author{
Sandra Lorena Hidalgo ${ }^{1}$ \\ Universidad de Cartagena
}

\section{Resumen}

¿Cómo interactúa el hombre con la realidad que le rodea, de qué manera aprehende de ella y la conceptualiza y categoriza para organizarla, comprenderla y comunicarla de manera eficaz a los demás? Friedrich Nietzsche nos muestra en su obra una profunda reflexión que, partiendo en gran parte de estos interrogantes, apunta a desentrañar la relación ser humano-realidad desde el lenguaje mismo, viendo éste como una herramienta que nos permite "descubrir" la realidad, fantaseándola por medio de palabras que sólo designan nuestras percepciones, mas no la realidad misma. El lenguaje, en este sentido, hará uso de la metáfora para mostrarnos que lo que llamamos "realidad" sólo es una construcción figurada desde el trabajo estético. Y el lenguaje científico, por otro lado, corresponderá a una organización "falsa", sólo encargada de fijar conceptos que, desde el lenguaje,

\begin{abstract}
How do Men interact with their surrounding reality? How do they learn from it to organize it, comprehend it and communicate it to others in a proper way? In his works, Frederich Nietzsche shows us a thoughtful reflection that takes these very same interrogatives into account in order to disembowel the nature of the relationship between Men and Reality. This reflection parts from the language itself, which is seen as a tool that allows us to "discover" Reality, recreating it by words that designate not the reality itself, but our mere perception of it. For this reason the language of literature will use the metaphor to let us realize the fact that what we call "Reality" is nothing but a construction of Language that takes its form in aesthetic endeavors. Scientific language on the other hand, corresponds with a "false" organization, which only purpose is to fixate concepts that men
\end{abstract}

${ }^{1}$ Docente del programa de Filosofía de la Universidad de Cartagena. e-mail: lorenakat@gmail.com 
el ser humano ha configurado, tratando de abarcar y simplificar una realidad que siempre se mostrará extensa e inaprensible.

Palabras clave: metáfora, realidad, representación, lenguaje artístico-literario, lenguaje científico. have configurated at the level of Language to encompass and simplify a reality that will always show itself as extensive and elusive.

Key words: Metaphor, Reality, Representation,Literary-Artistic language, Scientific language.

\section{Introducción}

Para Nietzsche el problema de la comprensión de la realidad parte de que, al tratar de ser aprehendida, ésta no sólo resulta esquiva al hombre, sino que, además, se muestra hostil, pues revela que en el complejo entramado de seres y cosas que la componen los seres humanos somos sólo una pieza, prescindible, por lo demás. Ante esta situación de desamparo el hombre se ve obligado a crearse una segunda naturaleza que pueda sobreponer a la realidad primera como mecanismo de defensa, tal como lo expone en su ensayo "Sobre verdad y mentira en sentido extramoral". Esta labor, de acuerdo con Nietzsche, será llevada a cabo, en primera instancia, por el lenguaje $\mathrm{y}$, posteriormente, por la ciencia.

El lenguaje, en primer lugar, porque reemplaza la experiencia de la cosa por la palabra que la designa, haciendo con ello un ejercicio de metaforización más que de descripción. Posteriormente, la ciencia, con ayuda del lenguaje, tratará de imponer una experiencia más generalizada de la sensación que se tuvo de las cosas, construyendo de esta manera categorías que permitan dar un cierto orden al mundo. Frente a estas pretensiones, sin embargo, Nietzsche señalará que por medio de estos recursos, del lenguaje y de la ciencia, no se puede alcanzar la Verdad, ya que lo único a que el lenguaje puede aspirar es a designar las relaciones que se dan con las cosas a través de metáforas, $\mathrm{y}$ todo desde una perspectiva completamente antropomórfica: a la realidad le resulta completamente ajena cualquier categoría desde la cual pretendamos reducirla al tamaño de nuestra comprensión. Pensémosla como la pensemos, ella seguirá resultando indefinible. De forma tal que sólo quedamos los humanos y nuestras metáforas para representar lo irrepresentable.

No obstante, al redimensionar al lenguaje como una herramienta humana, de naturaleza simbólica y metafórica, vinculada de manera 
instintiva a nuestra existencia en el mundo, Nietzsche replanteará con ello el uso metafórico del lenguaje como posibilidad de llevar al hombre hacia un nuevo modelo de pensamiento más vivo, más natural, más próximo a lo que la realidad constitutiva es: apariencia, cambio, devenir. Sólo transformandóse en artista, el hombre puede hacer un uso consciente de su capacidad de ficción para crear realidades bellas que le hagan cómoda la existencia, sin que por ello nieguen su carácter de transitorias, lo cual debe ser, para Nietzsche, la condición característica de toda verdad: la elección consciente y no la aceptación ciega.

\section{De las cosas sólo podemos hablar... metafóricamente}

\section{Realidad y lenguaje}

Para Nietzsche la realidad es caos y devenir. Es caos por cuanto ella contiene toda la multiplicidad de cosas existentes, además de sus contrarios, y es devenir porque en ella no hay nada fijo, estático o que permanezca inmutable a través del tiempo. En este sentido, tratar de aprehender la realidad con nuestras facultades mentales o con nuestras pobres redes conceptuales es tratar de abarcar el mar con la cuenca de la mano: se hace evidente que la realidad nos rebasa y nos supera hasta el punto de resultarnos incognoscible en su riqueza y en su totalidad. Nietzsche anota además en "Sobre mentira y verdad..." que el hecho de que la realidad se nos presente simultáneamente como un todo genera en nosotros una sensación de angustia y desconsuelo. Nos vemos abocados a contemplarnos en un plano de existencia igual al de los demás animales y las plantas, constatando que, al igual que ellos, nos hallamos expuestos a las fuerzas de la naturaleza y sufrimos la misma transitoriedad de aquellas criaturas que desconocen la finitud de su temporalidad.

Ante esta indigencia e incapacidad de controlar lo que le rebasa, el hombre -afirma Nietzsche- ha creado una "segunda naturaleza" a la que pueda controlar, para que de esta forma la originaria no le resulte tan amenazante o sobrecogedora (2000h). Para ello, se ha servido del lenguaje como una herramienta que ha permitido la construcción de un mundo de símbolos artificiales que le posibiliten moverse con tranquilidad en la realidad natural. Por medio del lenguaje es posible superponer dicha creación simbólico-conceptual a la realidad y, de esta manera, antropomorfizarla. Es decir, reducirla a la medida humana. En "Sobre verdad y mentira en sentido extra moral" (2000h), Nietzsche describe este procedimiento al referir cómo el conocimiento que en primera instancia tenemos de las cosas es un impulso nervioso dado a nuestros sentidos. Esta excitación de los nervios, posteriormente, produce en nosotros una imagen mental 
del aspecto que percibimos de la cosa dada a la sensación. Pero esta imagen, señala Nietzsche, es ya una construcción alejada en un grado de la cosa misma, y aun yendo más lejos, tratamos de expresar dicha imagen mental mediante palabras y signos que se hallan a otro grado de distancia, haciendo con ello más remoto aún el conocimiento de la cosa tal y como ésta era. De suerte que aquello que logramos comunicar no es más que una representación lingüística de una representación mental, no la cosa en sí.
¿Qué es una palabra? La reproducción en sonidos de un impulso nervioso. (...) Éste (el lenguaje) se limita a designar las relaciones de las cosas con respecto a los hombres y para expresarlas apela a las metáforas más audaces. ¡En primer lugar un impulso nervioso extrapolado en una imagen! Primera metáfora. ¡La imagen transformada de nuevo en un sonido! Segunda metáfora. Y, en cada caso, un salto total desde una esfera a otra completamente distinta (Nietzsche, 1990: 3).

Es muy importante anotar que para Nietzsche tal procedimiento de expresar por medio de comparaciones o de figuraciones de sentido es propio del lenguaje artistico-literario. Pues, ¿qué es una metáfora, sino una representación por signos indirectos? Es así como discurre nuestro conocimiento: primero se siente, luego se crea la imagen de lo que se siente y después se transmite ese sentir de la forma más cercana posible a lo real. Pero a través de las palabras que, en tanto que imágenes de la sensación, operan como metáforas. Esto significa que el lenguaje sólo expresa la realidad en términos metafóricos. Ello equivaldría, no obstante, a aceptar que lo que conocemos de la realidad, lo que creemos ver en ella de forma literal, es el resultado de un ejercicio de abstracción y no las cosas tal y como ellas son. Requerimos siempre comparar la sensación originaria con un término que exprese de manera semejante lo que ella dio bajo la forma de estímulo.

Esta idea no sólo nos resulta contraintuitiva, por cuanto en la experiencia cotidiana, al nombrar las cosas, sabemos de manera puntual a qué hacemos referencia, sino que choca, además, contra la idea de que como seres humanos somos racionales, y la razón es la facultad que precisamente nos permite dar cuenta de la realidad tal y como ella es, que se sirve del lenguaje como herramienta, no de aproximación, sino de adecuación entre la cosa y el nombre que la designa. 


\section{Ciencia y lenguaje conceptual}

Ahora bien, el valor del lenguaje se encuentra, entre otras cosas, en que hace patente la capacidad humana para conocer y controlar la realidad, actuando como un mecanismo de protección contra los caracteres caóticos y en devenir con los cuales se nos presenta la existencia. De ahí que una vez se ha solidificado el contenido de los nombres en conceptos, éstos empiezan a ser clasificados, organizados y jerarquizados en diferentes grados de complejidad por el discurso que llamamos científico. Esto le permite a la ciencia erigirse en un sistema de conocimiento, pero, a su vez, también favorece una forma de vida: la del hombre racional como opuesto al hombre sensitivo o instintivo que deposita su conocimiento en las percepciones.

Esta idea del hombre como ser racional, ligada a la concepción del lenguaje como adecuación, está estrechamente vinculada con la creencia moderna de que la ciencia y su método son la instancia superior de decodificación y validación de lo que ha de contar como verdadero. Para ello la ciencia se sirve de un uso muy particular del lenguaje, en donde éste adquiere las propiedades de ser intemporal y universal, gracias a que opera con signos que nombran las cosas de manera unívoca y gracias a que ordena las experiencias. Es decir, el lenguaje científico hace manejable lo que experimentamos como pura diversidad y transitoriedad. Este lenguaje científico es característicamente conceptual: sólo los conceptos permiten unificar lo que se nos presenta como diverso en la sensación, a la par que permiten mantener fijo lo que en la experiencia individual de la cosas se manifiesta como transitorio.

Es también superior a la percepción, porque la memoria de los sentidos respecto a los detalles constitutivos de cada cosa es pasajera, sin contar con que una misma cosa se presenta de múltiples maneras a nuestros sentidos (lo que supone la imposibilidad de establecer como base del conocimiento de la realidad los impulsos nerviosos primigenios); mientras que el lenguaje conceptual, por su parte, ofrece la ventaja de congelar la relación experiencia-palabra, pues al nombrar la cosa sabemos a qué se hace referencia sin necesidad de volver a la experiencia subjetiva de la cosa, impidiendo con ello el uso de la palabra con fines no legítimos o individuales.

Es importante para Nietzsche mostrar el desarrollo por medio del cual la ciencia, con ayuda del lenguaje, prescribe, a la par que un orden lógico racional para ordenar y clasificar los conceptos, una mirada "correcta" sobre el mundo y un modo lógico de ser de las cosas, ya que al hacerlo determina lo que ha de contar como legítimamente 
verdadero e impone que cualquier desviación o uso indebido de dicha clasificación se considere como falaz o ficticio, producto de un ejercicio libre de la imaginación. Lo singular de este uso del lenguaje es que, contrario a todas sus pretensiones, no es descriptivo sino prescriptivo, como lo señala Nietzsche, pues, en lugar de describir lo que hay en el mundo, nos dice qué cosas debemos ver del mundo. El asunto termina siendo una mera cuestión de elección lingüística: del uso que queramos hacer de palabras como "correcto" o "incorrecto", llevando con ello la verdad a categoría de acuerdo u obligación, imposibilitando, esta vez por vía científica, nuestro acceso a la realidad pura.

Cabe admirar en este caso al hombre como poderoso
genio constructor, que acierta a levantar sobre
cimientos inestables y, por así decirlo, sobre agua en
movimiento una catedral de conceptos infinitamente
compleja (...) Aquí él es acreedor de una admiración
profunda -pero no ciertamente por su inclinación a la
verdad, al conocimiento puro de las cosas-. Si alguien
esconde una cosa detrás de un matorral, a continuación
la busca en ese mismo sitio y, además la encuentra, no
hay mucho de qué vanagloriarse en esa búsqueda y ese
descubrimiento; sin embargo, esto es lo que sucede con
la búsqueda y descubrimiento de la "verdad" dentro del
recinto de la razón. Si doy la definición de mamífero y a
continuación, después de haber examinado un camello,
declaro: "he aquí un mamífero", no cabe duda de que con
ello se ha traído a la luz una nueva verdad, pero es de
valor limitado; quiero decir, es antropomórfica de cabo
a rabo y no contiene un solo punto que sea "verdadero
en sí", real y universal, prescindiendo de los hombres
(Nietzsche, 1990: 7).

Así la ciencia opera bajo el presupuesto de que es posible el conocimiento, situando al hombre al margen de los objetos de estudio, y haciendo uso de los conceptos de manera aséptica, sin involucrar su subjetividad, desconociendo con ello que con los conceptos damos, precisamente, forma a las cosas, las separamos de la multiplicidad unificándolas con su referente. El uso que hacemos de los conceptos no se limita a indicar un significado. La selección que hacemos de los términos y la decisión de a qué características deben ser aplicados implica una selección del mundo y, por lo tanto, impone una interpretación de dicho mundo. Lo anterior se puede apreciar mejor a partir de la pregunta que el mismo Nietzsche propone en su ensayo antes citado: “¿Por qué el árbol es masculino 
y la planta femenina?"(1990: 4), queriendo enfatizar el hecho de que en la naturaleza no hay nada que de antemano pertenezca a un género o a otro. Tanto masculino como femenino son categorías de nuestro lenguaje, que en éste caso nos sirven para ordenar y simplificar aquello que vemos.

Con estas palabras, Nietzsche logra desenmascarar el impulso hacia la verdad como la aceptación de una ilusión cuyo propósito consiste en la construcción de conceptos que fijan una determinada perspectiva de los objetos. Esta superposición de una perspectiva sobre la totalidad sólo es posible gracias a que la razón se presenta como procedente de un orden superior al orden natural, llegando a ser todo nuestro aparato cognitivo un sofisticado sistema autoreferencial en el que la razón no está obligada a remitirse a nada por fuera de ella misma. Nietzsche señalará, por lo tanto, que el lenguaje conceptual no opera sobre la base de una realidad descifrada o matematizada (como veremos más adelante, no hay realidad alguna al margen de las interpretaciones). La búsqueda de la verdad no es una búsqueda por los sustratos últimos de la realidad. El impulso hacía la verdad, como lo denomina Nietzsche, pone al descubierto más bien el aspecto instintivo de los seres humanos (el de buscar seguridad y tranquilidad), a la vez que revela la capacidad de ficción humana para facilitar la comprensión de lo que permanece oculto o vedado a nuestro conocimiento. En palabras del autor, "reducir algo desconocido a algo conocido alivia, tranquiliza, satisface" (Nietzsche, 2000h: 7).

Estas reflexiones hacen explicitas dos consideraciones sobre las cuales está construida la cultura occidental. La primera de ellas resalta el uso conceptual del lenguaje científico como medio de simplificación de la realidad y como piedra angular del pensamiento lógico-deductivo, que en manos de la ciencia adopta la forma de garante del conocimiento verdadero de la realidad. Y la segunda consideración sobre la cual hemos construido nuestras sociedades radica en el hecho de que nuestra experiencia racional de las cosas es una experiencia lingüística social. Tanto la designación de nombres, como la posibilidad de describir y referenciar lo expresado con corrección, sólo es posible al interior de una comunidad que convenga y valide la manera cómo se ha de utilizar el lenguaje: si como interpretación de la cosa o como verdad establecida.

\section{Lenguaje y sociedad}

Para Nietzsche el interés por el conocimiento de la realidad no es la causa de la búsqueda de la verdad, sino más bien el resultado de un 
acuerdo tácito para evitar el conflicto que se generaría al confrontar la diversidad de percepciones y de perspectivas. La necesidad de mentir gregariamente no surge sólo como una pretensión individual de ser aceptados en el seno de la sociedad, sino que es, sobre todo, un mecanismo de control y de dominación. En la medida en que una metáfora es aceptada al interior de una comunidad, su uso se va solidificando. Es decir, el uso reiterativo hace que se vuelva costumbre, hasta que se olvida su origen, y empieza a ser tomada como verdad en sí misma y no como lo que era originalmente: una convención acerca de cómo designar algo.

Este traslado de lo ficticio hacia lo que se ha de tomar por verdadero muestra la influencia que ejerce el lenguaje en la consolidación de la sociedad humana. Para que una sociedad se configure como tal es preciso la aquiescencia de sus miembros sobre lo que ha de contar como verdadero o como falso y su respectiva transposición al orden moral en términos de bueno o malo. De tal forma que una vez se haya establecido el acuerdo comunitario estas designaciones se repetirán una y otra vez, pasando de generación en generación y, por acción del tiempo, se convertirán en verdades incuestionables, logrando con ello un "sentimiento de verdad" ajeno a su construcción lingüística.

\begin{abstract}
¿Qué es entonces la verdad? Una hueste en movimiento de metáforas, metonimias, antropomorfismos, en resumidas cuentas, una suma de relaciones humanas que han sido realzadas, extrapoladas y adornadas poética y retóricamente y que, después de un prolongado uso, un pueblo considera firmes, canónicas y vinculantes; las verdades son ilusiones de las que se ha olvidado que lo son, metáforas que se han vuelto gastadas y sin fuerza sensible, monedas que han perdido su troquelado y no son ya consideradas como monedas, sino como metal (Nietzsche, 1990: 4).
\end{abstract}

Asílas cosas, palabras como "verdadero" o "falso" no están supeditadas a la adecuación entre lo percibido y las cosas. Hablar de verdadero o de falso es hablar en términos relativos: estos conceptos sólo pueden ser usados adecuadamente al interior de una comunidad que ha fijado de antemano su aplicación y que ha decidido el uso correcto $o$ incorrecto al referirse a las cosas. Para Nietzsche es una constante tal uso del lenguaje. En la historia de la humanidad cada pueblo, cada sociedad y cultura que ha existido ha creado sobre sí un "cielo conceptual" que valida su interpretación del mundo. Ha creado lo que Nietzsche denomina una "logosfera" (1990: 5), que sirve como referente último y obligado de toda verdad que se quiera establecer. 
Ahora bien, si como habíamos afirmado anteriormente no hay nada en el mundo ni en nuestros predicados del mundo que nos permita aseverar que el mundo o la realidad es de la manera en que los predicamos, entonces es necesario aceptar que el mundo es de diversas maneras y que, en consecuencia, el conocimiento humano, en tanto predicación del mundo, sólo es posible como descripción de uno y sólo uno de sus aspectos: el que fue dado a la percepción de manera individual. La consecuencia que de ello se desprenderá es que cada interpretación que se haga del mundo sobre la base de la propia percepción será verdadera, pues haría referencia, al menos, a uno de los aspectos del mundo. Esto conllevaría a pensar la verdad en términos de interpretación y no de correspondencia, y aun más, en términos plurales y no como unidad, o en términos nietzscheanos, de forma perspectivista.

\section{Del lenguaje sólo podemos hablar... metafóricamente}

Al revelar la ilusión que subyace en la creencia de un lenguaje verdadero, Nietzsche revelará que todo lenguaje es metafórico porque transfiere la percepción que es sensorial, y por lo tanto irrepresentable, a un código comprensible a nuestro pensamiento. Nos permite introducir, de manera ilusoria, una adecuación entre las cosas y las cualidades que de ellas destacamos, realizando con esto un ejercicio de falsificación. Esto es, ir más allá de lo que las cosas son (bien sea que empleemos la analogía, la generalización o la reducción). Al establecer conceptualmente la semejanza entre lo no idéntico, haciendo uso de lo que es propio de la metáfora, la razón revela su verdadera naturaleza como creadora de figuras retóricas para transitar de manera segura en el mundo de ilusiones en que discurre nuestra existencia. Sólo desde este enfoque es posible restituir el lenguaje metafórico-literario en su calidad de fiel transportador de la experiencia sensorial como expresión del devenir, pues, a los ojos de Nietzsche, únicamente desde la multiplicidad de sentido que entraña la metáfora es posible representar la multiplicidad de caracteres que componen la realidad.

A este respecto vale la pena traer a colación la definición etimológica del término metáfora: tal palabra proviene del prefijo griego meta, que significa "más allá", y del sufijo fero, que a su vez significa "llevar". De lo que resulta "trasportar" o "trasponer". De acuerdo con este significado, utilizamos las metáforas para trasponer los límites que las cosas en su mudez nos imponen o para trasportar el recto de sentido de lo que se dice conceptualmente a una forma flexible, imaginativa. Entender el sentido originario del término "metáfora" nos permite dimensionar la razón en sus justas proporciones, como 
proveniente de la imaginación y no de la lógica. La razón evidencia su origen imaginativo a través de su capacidad inventiva. Cada vez que usamos sus constructos, los conceptos, establecemos relaciones que trascienden lo habitual, creando así realidades abstractas asequibles no ya a los sentidos, sino a la propia razón que les dio origen.

Este análisis le permite a Nietzsche afirmar que tanto nuestro lenguaje como nuestro conocimiento comparten un mismo origen, que no es otro que la capacidad humana de crear metáforas, las cuales nos sirven como arquetipos para la elaboración de otras construcciones más refinadas, pero que también resultan provenientes de la imaginación que dio origen a los modelos originales. Nietzsche subraya que, por tratarse de una de estas construcciones, la ciencia y todo su armazón conceptual ha sido edificada sobre las arenas movedizas de la imaginación. Deliberadamente ha desconocido que todo "conocer" no es más que seleccionar la metáfora: “(...) conocer es simplemente trabajar con la metáfora favorita de uno (...) porque la construcción de metáforas es el instinto fundamental del hombre" (Nietzsche, 1990: 8). En Escritos sobre retórica, por lo demás, afirmará que "Todo explicar y conocer propiamente no es más que poner un nombre a las cosas" (2000d: 21).

Las palabras, en tanto que lenguaje, y el conocimiento, como recreación de la sensación, son originaria y esencialmente metáforas: ambos son procesos retóricos. Y los procesos retóricos no apelan a la racionalidad como fuente de aceptación. Apelan a la forma y al sentimiento porque no tienen que luchar contra el prejuicio de demostrar que no proceden de un origen imaginativo. Nietzsche, sin embargo, no se queda en la denuncia. Su intención es continuar abriendo perspectivas de las cuales no teníamos noticia por estar atrapados en los usos dogmáticos del lenguaje. Para Nietzsche la condición de no ser posible el lenguaje sino a través de metáforas evidencia no tanto la incapacidad humana de alcanzar la verdad, sino la naturaleza creativa de los seres humanos, dando con ello un giro a la crítica hecha a la ciencia y a sus pretensiones.

Al contemplar la ciencia desde un nuevo ángulo de visión, Nietzsche advertirá que no es meramente uno de los recursos que inventamos frente al desamparo de nuestra temporalidad. Pues, en la medida en que se erige como creación humana, cumple la misma tarea originaria del lenguaje. Es decir, nos constituye como humanos, como seres sociales y culturales. Ahora bien, lo que no es permitido para Nietzsche es que olvidemos que esa construcción es producto de nuestra capacidad para metaforizar la realidad, que olvidemos que es nuestra creación y le concedamos un poder subyugador frente a 
lo que debe contar como verdadero o como real; que nos prescriba la manera cómo debemos vivir y sentir el mundo, descalificando todo aquello que no sea susceptible de designación o racionalización.

De suerte que lo que antes era utilizado como escudo protector contra lo doloroso y angustiante, ahora se presenta en forma afirmativa: El hombre se despoja de su papel de espectador para convertirse en un creador que no necesita servirse más de redes conceptuales, pues lo que antes era ilusión ha logrado transmutarlo en manejo consciente e intencionado del pensamiento metafórico. Pensamiento cuya esencia radica en hacer uso de las palabras y de los argumentos más sugestivos, dado que lo único verdaderamente efectivo para imponer una perspectiva por encima de otra es el lenguaje bello... el lenguaje retórico. Esto tiene su razón de ser solamente tras haber constatado que el lenguaje, como correspondencia, es una ficción en la que la verdad es interpretación; que sólo adquiere valor en la medida en que es un medio de persuasión. Esto es, la fuerza que deben tener mis palabras para convencer o el adorno que las acompaña para seducir a otros. De acuerdo con Nietzsche, convencer, persuadir, seducir, terminarán convirtiéndose en lo único realmente esencial a la hora de determinar nuestra transmisión de la realidad y la naturaleza de nuestra relación con los demás.

La aceptación de la idea anterior, sumada al hecho de que no existe la percepción correcta, conlleva a la identificación del verdadero origen del lenguaje como retórica y, más adelante, a ser una forma de afianzamiento de la vida como creación individual. Por lo pronto, la afirmación de que el lenguaje deviene en retórica procede de que, al intentar transmitir las excitaciones nerviosas que se dan al contacto con las cosas, no puede hacerlo: las palabras son imágenes de imágenes (como habíamos visto), y en la transmisión conceptual de la sensación que se hace a un tercero, ésta se encuentra mediada por un proceso de abstracción que degenera la sensación original y la transforma en una copia de la representación.

De suerte que lo que se logra transmitir es, en el mejor de los casos, un punto de vista subjetivo, una cierta apreciación de la cosas. En una palabra, una opinión con la cual tratamos de persuadir al otro de que eso que estamos refiriendo no es una imitación (por lo demás inexacta) de las cosas y de las sensaciones que estas nos produjeron, sino que tratamos de persuadirlo de la veracidad que tiene la sensación o la imagen seleccionada por nosotros... tornando al lenguaje en retórico y utilizándolo no como una herramienta para acceder a la verdad, como en un principio se quería mostrar, sino en una herramienta de falsificación. 
No obstante, al seducir a otros con palabras, ¿qué ganamos con ello? Nietzsche logra entrever que, más allá de la comodidad proveniente del tratado de paz que conquistamos con la unidad de percepciones, existe otro interés que alienta el uso consciente de la retórica como visión auténtica (original, primaria, no "verdadera") de la realidad:

\begin{abstract}
Mis escritos afirman constantemente que el valor del mundo se encuentra en nuestra interpretación (que acaso en cualquier otro lugar son posibles otras interpretaciones distintas de las simplemente humanas); que las interpretaciones hasta ahora admitidas son evaluaciones perspectivas, en virtud de las cuales nos conservamos en la vida, o sea en la voluntad de poderío, en el aumento del poderío; que toda elevación del hombre lleva consigo la superación de interpretaciones más restringidas; que cada consecución de nueva fuerza y de extensión del poder abre nuevas perspectivas y significa creer en nuevos horizontes. El mundo que nos interesa es falso, esto es, no un hecho, sino una imaginación y un englobamiento de una escasa suma de observaciones; es fluido, como una falsedad que continuamente se desvía, que no se acerca nunca a la verdad, porque no hay "verdad" ninguna (Nietzsche, 2002: III, 359).
\end{abstract}

Aparece así la propuesta nietzscheana en su real dimensión: transvalorar los usos del lenguaje para que con ellos cambien también los modos de pensar y éstos a su vez al hombre, restituyéndolo en su libertad originaria de sentir sin la directriz de un dogma y sin el peso del valor absoluto. Sólo realizando dicha "transvaloración lingüística" es posible pensar en el lenguaje metafórico como un arma suficientemente poderosa para hacer del hombre un ser individual, que no oculte su diferencia tras lo gregario y, sobre todo, que tenga la fuerza para vivir su vida como un fenómeno estético. De suerte que conceptualizar la realidad en términos científicos haría parte de un ejercicio ya no de adecuación, sino de creación como comportamiento artístico de quien elige hablar en términos lógico-conceptuales para transformar lo inabarcable en cantidades mensurables. Por otra parte, la antropomorfización del mundo, junto con la adopción de pensamientos verdaderos cuando en realidad no lo son, harían parte del juego de fuerzas en constante lucha que es la vida, que en palabras de Nietzsche no es otra cosa que la aceptación de que el "objetivo del conocimiento -en tanto ficción o apariencia-, no es saber, en el sentido de comprender la verdad absoluta en sí misma, sino controlar"(1990: 7). 
Ya antes habíamos asegurado, sin embargo, que la realidad no es abarcable ni controlable por nosotros. De lo que se sigue que, con este juego, ya no se busca prescribir una mirada correcta del mundo. A lo que apunta Nietzsche es a proponer una forma particular de vida en la cual sea deseable y lícito captar la realidad más allá de categorías como verdadero-falso, o en sus palabras, "más allá del bien y del mal". La expresión "más allá del bien y del mal” se refiere a dejar atrás la búsqueda transmundana de ideales como bien, dios o verdad, junto con sus opuestos, y concentrar todo el esfuerzo inventivo en el uso de términos más cercanos a la vida, al cuerpo, a lo fisiológico. La importancia de enraizar el lenguaje a la vida tiene su valor práctico en que cambiar el lenguaje es cambiar la forma de valorar, e implica que si el hombre ha de asirse a algo como mecanismo de protección, ese "algo" debe estar al alcance de su mano, debe tener la medida de lo que pueda agarrar. Es decir, aquellas cosas que antes eran descartadas por ser consideradas pequeñas, pero que, en últimas, son las verdaderamente esenciales para el hombre.

Ocuparse de cosas aparentemente sin importancia como la alimentación, el clima, el lugar, los sentidos, la sensaciones, lo que es bueno para el cuerpo y para la vida, en lugar de la suprema importancia que se le ha dado a lo moralizado como virtud, pecado, sentimiento de culpa, flagelación, más allá, Dios, sugiere justamente comenzar a cambiar lo aprendido (Cf. Nietzsche, 2000f: 50) No es otra cosa que transmutar las preocupaciones por el lenguaje en preocupaciones por el cuerpo. Abandonar la verdad en favor de la vida es liberarse del poder que ejercía el símbolo como dador de realidad para adentrarse en el arte, en lo estético, en la libre creación.

\section{A manera de conclusión}

\section{De la ciencia sólo podemos hablar... estéticamente}

Cuando Nietzsche transmuta el valor del conocimiento en creación estética no está recubriendo el viejo ídolo con ropajes nuevos: esto sería propio del obrar transmundano. Para Nietzsche la estética debe ser, ante todo, fuente de transformación del mundo y de la existencia. Debe estar al servicio de la vida y de los instintos que le dieron origen, que la han fortalecido y la han exaltado. Así toda actividad creativa que le sirva al hombre para la creación de sí mismo tendrá cabida dentro del concepto de arte. Por ello es enfático al afirmar que la ciencia, antes de ser lenguaje de las cosas o de la realidad, es arte: como discurso lógico-conceptual se usa en sentido retórico de manera consciente para llevar a cabo la transpolación del sentido, apareciendo así la verdadera condición del conocimiento, pues este 
no se propone ya como herramienta de control de la realidad, sino "como condición estética de la existencia" (Nietzsche, 2000d: 3).

Demarcada la ciencia por los límites dellenguajey por ser escasamente una copia de las sensaciones originarias, el conocimiento que de ella se deriva es un conocimiento aparente y precisamente es allí donde coincide con el arte. Son los límites de la ciencia los que la transforman en un arte: en la medida en que la ciencia transforma la realidad en algo al alcance de nuestras representaciones, privilegia una forma de vida dentro de la cual el científico no es un dominador, sino un interprete de la realidad, tornándose en un artista capaz de desplazar la multiplicidad de perspectivas por una perspectiva en particular que intenta hacer valer como la "normal". Todo lenguaje, todo discurso y todo concepto abandonan así el carácter de adecuación con las cosas, para vincularse al campo de la estética como impulsos conscientes de ilusión, como "desviación consciente de la realidad que se encuentra en el mito, el arte, la metáfora" (Nietzsche, 1990: 11). Es decir, en la naturaleza artística del lenguaje se revela la naturaleza artística del hombre como constructor de símbolos, de artificios mediante los cuales es posible expresar nuestra relación con las cosas como producto no de una adecuación sino de una relación de fuerzas instintivas e irracionales. La retórica es, sobre todo, una fuerza, la fuerza del lenguaje.

Debido a que el lenguaje como herramienta humana de naturaleza simbólica, según Nietzsche, se superpone a la realidad sin separarse enteramente de ella, el hombre no sólo permanece vinculado por el instinto de adaptación con aquello que lo sobrepasa, que le revela su contingencia y fragilidad, sino que, no hallando otro medio para la conservación que la invención de realidades, debe escoger aquellas que lo mantienen unido a la naturaleza. Este tipo de vinculación no precisa la creación de otras realidades, porque pone los mismos instintos que sirvieron para creación consciente de artificios al servicio de la vida, de la cual él es, al mismo tiempo, conocedor y prueba por hacer parte de ella. Así lo expone Nietzsche:

La metafísica, la moral, la religión, la ciencia son tomadas en consideración sólo como diversas formas de mentira: con su ayuda se cree en la vida. "la vida debe inspirar confianza": el deber planteado en estos términos es inmenso. Para cumplir con él, el hombre debe ser por naturaleza un mentiroso, debe ser antes que ninguna otra cosa, un artista... Y de hecho lo es: metafísica, moral, religión, ciencia, no son más que criaturas de su voluntad de arte, de mentira, de huida ante la "verdad", 
de negación de la "verdad". Esta facultad misma, gracias a la cual él violenta la realidad por medio de la mentira, esta capacidad de artista par excellence del hombre -él la tiene en común con todo lo que es: pues él mismo es un pedazo de realidad, de verdad, de naturaleza- él mismo es también un pedazo de genio de la mentira (Nietzsche, 1994: Af. 125, 415).

Para Nietzsche, la única manera de traspasar los abismos de la existencia es a través de la actividad creadora. Actividad que ha de comenzar por el interior del hombre mismo, siendo así que esta actividad creadora no parte de la obra de arte para desde allí transformar al hombre. La obra de arte es posterior al hombre que se ha creado a sí mismo, que ha producido su propia vida a partir de la creación de formas de engaño que le permiten habitar el mundo de una manera cómoda y segura, pero, por sobre todas las cosas, que han sido su elección y no que han venido bajo la forma de miradas únicas o concepciones "correctas" de la realidad. En esto se diferencia el artista de los demás hombres: él sabe que su elección no está respaldada por ninguna realidad, que no descansa sobre las bases de la razón o de la verdad. Conoce que tras su obra se sigue escondiendo todo lo terrible de la existencia, todo lo transitorio y efímero que ésta puede llegar a ser, todos los abismos insondables y todas las cimas inalcanzables, $y$, sin embargo, elige a sabiendas que su elección es un engaño necesario. Sueña sabiendo de antemano que eso que se representa es lo que está soñando.

Toda ensoñación, al igual que toda actividad creadora realizada por el hombre, tiene su lugar en el arte. En éste se patentiza lo universal y omniabarcante, gracias a que sólo el arte es capaz de dar cuenta de la multiplicidad de fuerzas y momentos que constituyen la realidad. El arte es un lenguaje de posibilidades que se reconoce a sí mismo como fundado en las sensaciones que son la fuente de cualquier existencia humana. Lo cual significa que sólo es posible en un hombre que no esté en pugna con la vida, un hombre que es capaz de pensarse a sí mismo desde una categoría diferente a la razón, que puede y quiere colocar el cuerpo, el instinto, el arte, como centro de gravedad de la vida.

Fundamentando el arte en los instintos, Nietzsche inaugura la noción de "arte como fisiología", de la cual el artista es la encarnación. Es él quien ha logrado trascender las rígidas verdades antropomórficas para imitar la vida en su capacidad de creación y de destrucción de apariencias. La figura del artista, en cuanto creador de su propia vida, dota a la existencia con un nuevo sentido mucho más poderoso que 
el conocimiento, porque al rescatar la multiplicidad de sensaciones, y al afirmar la fisiología y los sentidos como fuente de conocimiento, logra representar de manera más esencial el carácter transitorio y plural de las cosas. Al expresar siempre de forma diferente lo que en las cosas está mudando se enriquece el conocimiento que de éstas se puede llegar a conseguir.

Para lograr este acercamiento de lo inequívoco que hay en la realidad, el artista tuvo que cosechar una Voluntad dotada de una fuerza tal que le permitiera situarse en un mundo sin verdades: el concepto de verdad sólo podía tener cabida en un tiempo histórico como el creado por el hombre; para erguirse en el mundo de la realidad, del devenir, es necesario ejercitarse en la creación a partir de la nada. Es preciso estar dotado de un deseo de superación de la verdad elegida anteriormente, porque sólo así el hombre será realmente un creador de realidades que no estén mediadas por los conceptos:

\begin{abstract}
El arte, ligado a la generación y sobre todo justificación de la apariencia, es de nuevo para los individuos un lenitivo necesario frente a la verdad reconocida, en este caso el hecho de que la especie vive en el error: El arte nos da la buena conciencia para ver el mundo como un fenómeno estético y aceptar este mundo de apariencias, ilusión y mentiras vitales (Nietzsche, 2005: Af. 107, 124).
\end{abstract}

Entonces la realidad dejará de ser algo de lo cual hay que protegerse y empezará a ser el lugar en el que el ser humano pueda contemplarse a sí mismo junto a los otros seres, libre del temor de pasar y desaparecer, pues gracias a que su Voluntad se ha desplegado en diferentes formas: lenguaje, filosofía, ciencia, arte, ha hecho posible la vida, ha transfigurado el horror en belleza, en arte... Pero nunca renunciando a su origen de aparentes, de encubridoras de lo real. Al hacerlo, el hombre configura una forma superior de práctica, de ser, de vida, como aquel que, debiéndose a la vida, fue capaz de crearse a sí mismo.

\title{
Bibliografía
}

Habermas, Jürgen. (1982). "La crítica nihilista del conocimiento en Nietzsche" en Sobre Nietzsche y otros ensayos. Madrid: Tecnos. (Traducción de Carmen García Trevijano y Silverio Cerca).

Nietzsche, Friedrich. (1994). Fragmentos póstumos. Barcelona: Edhasa. editores. (1995). Ditirambos de Dionysos. Bogotá: El Ancora (1996). Humano, demasiado humano. Barcelona: Akal. 
(1997). Así hablaba Zaratustra. Barcelona: Círculo de Lectores.

(2000a). Ecce homo. Madrid: Alianza Editorial.

(2000b). El Crepúsculo de los ídolos. Madrid: Alianza

Editorial.

(2000c). El nacimiento de la tragedia. Madrid: Alianza

Editorial.

(2000d). Escritos sobre retórica. Madrid: Editorial

Trotta.

(2000e). La genealogía de la moral. Madrid: Alianza

Editorial.

(2000f). El anticristo. Madrid: Alianza Editorial.

(2000g). Más allá del bien y del mal. Madrid: Alianza

Editorial.

(2000h). Sobre verdad y mentira en sentido extra moral. Madrid: Editorial Tecnos.

(2002). La voluntad de poder. Madrid: Aguilar. (2005). La gaya ciencia. Madrid: Eimat. 